\title{
Socialismo e democracia: Bobbio e os marxistas italianos 1
}

MARÍA DEL GARMEN GORTIZO"

\section{Resumo}

O trabalho apresenta alguns aspectos do debate mantido entre Norberto Bobbio e intelectuais vinculados ao Partido Comunista Italiano $(\mathrm{PCl})$ sobre a teoria marxista do Estado, entre 1975 e 1976. Nas discussões, são explicitados os elementos teóricos que fundamentaram a construção da "via italiana ao socialismo", a participação do $\mathrm{PCl}$ na vida parlamentar italiana, e a afirmação da "democracia como valor universal". Os temas que constituem o centro do debate são, por um lado, a crítica ao modelo soviético e a afirmação da necessidade da socialização do poder político além da socialização da economia, e, por outro, a incorporação crítica dos direitos individuais e dos procedimentos da democracia representativa burguesa aos projetos políticos socialistas.

Palavras-chave: Socialismo. Democracia. Marxismo italiano. Norberto Bobbio.

\footnotetext{
* Universidade Federal de Santa Catarina (Brasil)

${ }^{1} \mathrm{O}$ presente trabalho faz parte da pesquisa realizada em 2013 durante o Pós-Doutorado na Universidade de Turim, Itália, com financiamento da CAPES.
} 
Socialism and Democracy: Bobbio and the Italian Marxists

\section{Abstract}

The paper presents some aspects of the debate held between Norberto Bobbio and intellectuals linked to the Italian Communist Party $(\mathrm{PCl})$ on the Marxist theory of the state, between 1975 and 1976. In this discussion, the theoretical elements that underlie the construction of the "Italian road to socialism" with the participation of the $\mathrm{PCl}$ in the Italian parliamentary life and the affirmation of "democracy as a universal value" are detailed. At the center of this debate lie, on the one hand, a critique of the Soviet model and the affirmation of the need for socialization of political power beyond the socialization of the economy; and, on the other hand, the critical incorporation of individual rights and the procedures of bourgeois representative democracy into the socialist political projects.

Keywords: Socialism. Democracy. Italian Marxism. Norberto Bobbio.

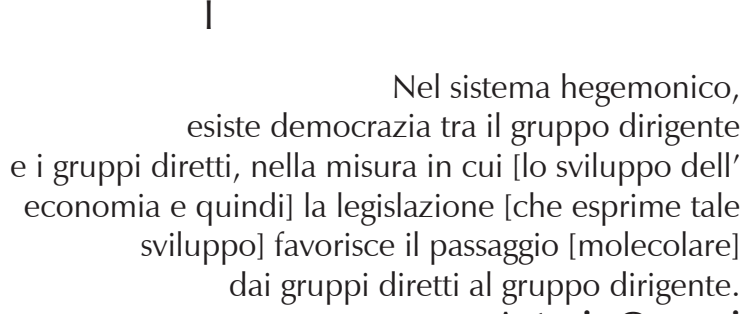

Antonio Gramsci

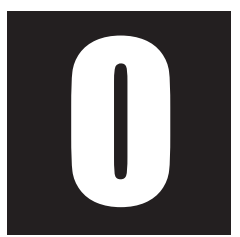

tema do presente trabalho surge das inquietações teóricas sobre o problema das instituições jurídico-políticas necessárias à efetivação de um projeto de transformação radicalmente democrático e plural da sociedade, no âmbito da teoria marxista.

Na tradição marxista, a questão do vínculo entre socialismo e democracia está presente desde o início, a começar pelos primeiros escritos de 
Marx (Crítica à Filosofia Hegeliana do Direito Público, A Questão Judaica, A Guerra Civil na França), passando pelas polêmicas entre "revisionistas" e "ortodoxos", entre Bernstein e Kautsky, entre Rosa Luxemburgo e Lênin e Trotski (Coutinho, 1984; Sánchez Vázquez, 2001).

Mas, com Gramsci, a questão democrática coloca-se em novos termos que estabelecem as bases teóricas para pensar a construção da hegemonia e a transição ao socialismo em formações sociais complexas. $\mathrm{O}$ assunto da conquista e do exercício do poder político em sociedades de tipo "ocidental" adquire uma particular dimensão no marxismo italiano do século XX, que elabora, na década de 1950, sob a direção de Palmiro Togliatti, a denominada "via italiana ao socialismo" (Mondaini, 2011; Togliatti, 1980), chegando à afirmação da democracia como "valor universal", realizada por Enrico Berlinguer - Secretário do Partido Comunista Italiano (PCI) - no emblemático discurso pronunciado em Moscou em 1977, durante as comemorações dos sessenta anos da Revolução Russa. Diante de centenas de dirigentes comunistas da URSS e de todas as partes do mundo, afirmou:

O Partido Comunista Italiano também surgiu sob o impulso da Revolução dos Sovietes. Ele cresceu depois, sobretudo porque conseguiu fazer da classe operária, antes e durante a Resistência, a protagonista da luta pela reconquista da liberdade contra a tirania fascista e, no curso dos últimos 30 anos, pela salvaguarda e o desenvolvimento mais amplo da democracia. A experiência realizada nos levou à conclusão — assim como aconteceu com outros partidos comunistas da Europa capitalista - de que a democracia é hoje não apenas o terreno no qual o adversário de classe é forçado a retroceder, mas é também o valor historicamente universal sobre o qual se deve fundar uma original sociedade socialista.

Eis por que a nossa luta unitária - que procura constantemente o entendimento com outras forças de inspiração socialista e cristã na Itália e na Europa Ocidental — está voltada para realizar uma sociedade nova, socialista, que garanta todas as liberdades pessoais e coletivas, civis e religiosas, o 
caráter não ideológico do Estado, a possibilidade da existência de diversos partidos, o pluralismo na vida social, cultural e ideal (Berlinguer, 2006).

Nesse discurso estão contidos todos os elementos que permitiram ao $\mathrm{PCl}$ constituir-se como uma das principais forças políticas da Itália: surgido sob o impulso da Revolução Bolchevique, o partido se fortaleceu na luta contra o fascismo, desenvolvendo um papel decisivo de organização e direção da Resistência, e nesse processo conseguiu construir o protagonismo das massas operárias. Acabada a guerra, participou na elaboração da Constituição de 1947, assumindo o compromisso da sua salvaguarda, a partir de uma concepção de democracia como terreno da luta de classes e como "valor universal" de uma sociedade socialista. Consequentemente defendeu a necessidade de formular alianças com as forças socialistas e cristãs e a garantia das liberdades pessoais e coletivas, do caráter não ideológico do Estado e do pluralismo partidário, cultural e societário.

O Partido Comunista da Itália foi fundado em 1921 (como seção italiana da III Internacional), denominação que muda para Partido Comunista Italiano, em 1943. Gramsci e Togliatti participaram desse momento inicial, marcando - de formas diversas - a direção do percurso subsequente e, ao mesmo tempo, colocando as condições de possibilidade teóricas e políticas que levaram às posteriores cruciais transformações. No meio do caminho, ocorre o abrandamento das estreitas relações com a União Soviética, e a definição da "via italiana ao socialismo", que consistia na busca de uma "democracia progressiva", aplicando integralmente a Constituição Italiana de 1947, ou seja, a adesão à via democrática ao socialismo.

A construção da possibilidade de uma transformação radical da sociedade pela via da democracia parlamentar é um processo marcado pelas lutas antifascistas da Resistência e pelas características que fazem da Itália um país "sem revoluções". No Informe apresentado ao Comitê 
Sociologias, Porto Alegre, ano 17, no 38, jan/abr 2015, p. 254-279

Central do Partido Comunista Italiano em 24 de junho de 1956, Togliatti afirmava:

\begin{abstract}
Devemos continuar na busca e realização de um caminho nosso, de um caminho italiano de desenvolvimento para o socialismo. [...] O caminho italiano é um caminho que prevê um desenvolvimento no terreno democrático, de fortalecimento da democracia e de sua evolução no sentido de determinadas e profundas reformas sociais. Se não se coloca a questão desse modo, se faz uma sumária identificação exterior entre "caminho italiano" e "caminho parlamentar". [...] A utilização do parlamento é uma das possibilidades de desenvolvimento de uma ação consequentemente democrática para obter profundas reformas de estrutura. [...] Devemos ter presente o que Lênin dizia sobre o caráter ilusório da democracia burguesa. Podemos hoje pôr fim, em parte e até em grande parte, a esse caráter ilusório; ou seja, podemos criar um terreno verdadeiramente democrático sobre o qual se possa desenvolver vitoriosamente a luta pelo socialismo, assim como previam os clássicos do marxismo. [...] Pretendemos desenvolver, sobre o terreno democrático, a ação e a luta das massas operárias e trabalhadoras para modificar profundamente as estruturas econômicas da sociedade italiana (Togliatti, 1980, p. 154-157).
\end{abstract}

Assim, participando da vida democrática representativa, em 1976 o $\mathrm{PCl}$ obteve o seu máximo histórico de $34,4 \%$ nas eleições gerais, sendo que, no ano anterior, havia conquistado a administração municipal das principais cidades italianas. Não é o caso aqui de relatar a história do partido; sabemos que foi o maior partido comunista de Ocidente e que seu particular desenvolvimento o separou da política soviética e o fez criar uma nova concepção marxista da transformação social. Como afirma Alfredo Reichlin², referindo-se ao grupo de intelectuais comunistas que, a partir do início da década de 1960, renovou o PCl:

${ }^{2}$ Alfredo Reichlin foi membro da Secretaria, da Direção e do Comitê Central do PCI. 
O objetivo, ambicioso e temerário, era no fundo repensar a identidade do $\mathrm{PCl}$, no sentido de tornar indissolúvel o nexo entre democracia e socialismo. (...) A peculiaridade da sua posição consistia no esforço de pensar o comunismo italiano em termos inteiramente políticos, livrando-o de toda transcendência e de qualquer idéia autoritária da história. Sentiam-se seguidores do grande pensamento historicista italiano: Vico, Spaventa, Labriola. E buscavam sua confirmação no historicismo absoluto de Gramsci. (...) Pretendiam afirmar (...) a exigência de ultrapassar os velhos esquemas de um marxismo substancialmente economicista (Reichlin, 2009, p. 9-10).

$\mathrm{Na}$ busca dessa superação do marxismo economicista, os caminhos se entrelaçaram com Norberto Bobbio. Por esses motivos, o desenvolvimento do marxismo italiano mostra-se uma realidade histórica singular para refletir sobre a relação entre socialismo e democracia e sobre as formas jurídico-políticas necessárias à construção de projetos societários radicalmente democráticos.

No período compreendido entre a derrota do fascismo e meados da década de 1970, sucederam-se na Itália importantes debates entre intelectuais liberais, socialistas e marxistas, no decorrer dos quais aparecem os princípios que levaram o $\mathrm{PCl}$ a renunciar à tomada violenta do poder e a participar da vida democrático-parlamentar através da denominada "via italiana ao socialismo", com o consequente progressivo afastamento do modelo soviético e das concepções que, dentro do marxismo, identificavam democracia política com dominação burguesa, abrindo passo para mais uma etapa nas discussões sobre o vínculo entre socialismo e democracia. Dentre esses debates, tomamos como referência para o presente ensaio - pela sua relevância teórica e política - aquele travado entre Norberto Bobbio e um grupo de intelectuais vinculados ao $\mathrm{PCl}$ a respeito do marxismo e do Estado entre os anos 1975 e 1976. 
Mas, para compreender criticamente as condições objetivas que possibilitaram essa relação de diálogo e debate entre um filósofo liberal e intelectuais comunistas, partimos do pressuposto - que não, por óbvio, deixa de ser significativo - de que nem todo e qualquer liberalismo e nem todo e qualquer socialismo podem dialogar em busca do que Nogueira (2001, p. 19-20) denomina uma "integração virtuosa":

Isso significaria que nem todo liberalismo e nem todo socialismo podem dialogar e buscar uma integração virtuosa. Os interlocutores precisam estar qualificados não só por uma sólida convicção doutrinária, mas também pelo abandono de toda intolerância arrogante. No horizonte, um feixe de coisas compartilhadas, muita disposição política e uma enorme capacidade de criar vínculos ativos com forças sociais ativas. Afinal, diálogo e integração só podem existir se os interlocutores tiverem consciência plena de si: uma identidade e um patrimônio a serem preservados.

Qual é essa identidade e esse patrimônio a serem preservados? Pensamos que o diálogo entre Norberto Bobbio e os comunistas italianos foi possível devido a pelo menos dois fatores: em primeiro lugar, o fato de que a Resistência colocou lado a lado grupos provenientes de ideologias contraditórias: comunistas, socialistas, liberais e católicos lutaram a mesma batalha; Bobbio e vários dos seus interlocutores participaram ativamente dessa luta.

Em segundo lugar, a forte presença de dois intelectuais - liberal um, marxista o outro - que, no início do século XX, refletiram sobre a história da Itália e sobre o surgimento do fascismo, colocando em primeiro lugar a questão cultural. Referimo-nos a Piero Gobetti e a Antonio Gramsci, "os maiores protagonistas da história cultural italiana do século XX" (Bobbio, 1984, p. 7). Ambos viveram e padeceram os tempos de surgimento e 
consolidação do fascismo, uma vez deflagrada a crise do Estado liberal e fracassadas as duas grandes correntes políticas do Novecentos: o liberalismo e o socialismo.

Piero Gobetti nasce em 1901 e morre em 1926, aos 25 anos. A sua atuação militante se estende por apenas sete anos, escreve o primeiro artigo em 1918 e o último em 1925. Como diz Bobbio (1984), esses sete anos são para Gobetti o percurso inteiro de uma vida, nos quais parece consumar e completar a sua obra. Durante esse curtíssimo período de tempo, desenvolve uma inédita e original perspectiva na qual convergem dois termos aparentemente antitéticos: liberalismo e socialismo, em nome de dois elementos implícitos tanto na "concepção de mundo" liberal quanto na socialista: o conflito como princípio e a autonomia como valor. Por esse ponto de vista, o socialismo revolucionário - entendido como a luta concreta e intransigente do proletariado pela própria liberação - é a forma histórica mais avançada e completa do liberalismo, liberalismo que se identifica com a força social que opera de modo revolucionário, ou seja, com o movimento revolucionário da classe operária.

Bobbio (1984) sistematiza os três princípios dessa particular concepção gobettiana que identifica o liberalismo com a luta pela liberdade e com a ação histórica dos setores interessados: 1) a atitude antiestatista; 2) a importância crucial do tema da autonomia; 3) a concepção antagonista e agonista da história. Sobre este último tema, Gobetti tem a convicção de que o progresso histórico depende do contraste, da luta, do embate dos interesses e das ideias. Parece ver no conflito a nova forma do vínculo social, aquilo que coloca em relação - solidária e antagônica - as pessoas, de modo tal a permitir a formulação de soluções unitárias em nível estatal, na seleção de uma classe política representativa dos grupos em conflito e na definição de equilíbrios dinâmicos, que colocam o Estado como momento provisório de sínteses sempre ameaçadas por novas relações de força e sempre repropostas em níveis superiores. 
Sociologias, Porto Alegre, ano 17, no 38, jan/abr 2015, p. 254-279

O outro elemento fundamental para Gobetti é a autonomia, entendida como poder ascendente contraposto ao poder descendente, ou seja, o princípio de governo construído de baixo. Mas a autonomia também é identidade irredutível, capacidade dos grupos e dos indivíduos de colocar-se per se, de afirmar no tempo a própria convicção (coerência) e de constituir-se no confronto com o outro, originando contraste, contraposição. Daí a importância da ética da convicção assumida como garantia da não neutralização do conflito e a defesa da luta - no limite da guerra civil -, entendida como expressão máxima de novos anseios e de novas grandezas.

Do socialismo, Gobetti apreende somente dois princípios: 1) a luta de classes e a forma da revolução, que somente poderá ser uma revolução proletária; e 2) o protagonismo das vanguardas do movimento operário, únicas a demonstrar nesse momento histórico uma identidade irredutível. Além desses princípios, é hostil ao socialismo, sendo sua teoria da política e da liberdade substancialmente elitista. Por esses motivos, Revelli (1994) define Gobetti não como um liberal-socialista, nem como um liberal-comunista, mas como um liberal-bolchevique.

O outro grande protagonista da história cultural italiana do século XX, Antonio Gramsci, nasceu em 1891 e morreu em 1937, também, como Gobetti, vítima do fascismo. A sua obra transcende o mundo italiano e, até hoje, é fonte de análises e controvérsias. Para efeito da presente argumentação, faremos referência apenas a algumas das elaborações teóricas que abriram a possibilidade para o desenvolvimento da "via italiana ao socialismo" e para o diálogo dos comunistas com outras forças políticas. Nesse sentido, são fundamentais a sua concepção de "hegemonia" e de "guerra de posição" no contexto do projeto de transformação social por ele defendido.

Cerroni (2008, p. 99) assinala três elementos-chaves na teoria da hegemonia de Gramsci: 1) a supremacia de um grupo social se manifesta em duas formas: como "domínio" ou coação, e como "direção intelectual 
e moral" ou consenso; 2) um grupo social é dominante sobre os grupos adversários e dirigente em relação aos grupos afins ou aliados; 3) um grupo social pode e deve ser dirigente já antes de conquistar o poder.

Nesse sentido, para tornar-se dirigente e conquistar o poder, Gramsci assinala duas estratégias: a "guerra de movimento" e a "guerra de posição". Segundo Cerroni (2008, p. 98), nessa distinção, de alguma forma está implícita a diferenciação entre dois tipos diversos de estratégias da revolução socialista, assimiláveis respectivamente à estratégia da violência e àquela da "via democrática". Distinção que reenvia à diversidade da conformação histórica de Oriente e Ocidente, e às características das sociedades capitalistas desenvolvidas nas quais a sociedade civil é uma estrutura muito complexa e resistente às irrupções catastróficas do elemento econômico imediato (crises, depressões). Desse modo, Gramsci estaria impugnando a absolutização do método da revolução violenta e afirmando, por um lado, que a guerra de posição também pode conduzir à vitória, e, por outro, que essa guerra exige uma concentração inaudita de hegemonia.

Mas a hegemonia não é uma simples combinação de domínio e consenso, senão hegemonia social relativa ao consenso espontâneo dado pelas grandes massas à direção da vida social imposta pelo grupo fundamental, visando conseguir o consenso de grupos e forças sociais na luta contra as forças dominantes, ainda antes de conquistar o poder. Para Gramsci, a supremacia de um grupo social se manifesta de duas maneiras: como domínio e como direção intelectual e moral. Como assinala Piñon (1989, p. 274), Gramsci não é partidário de um ingênuo democratismo, que se contenta com as liberdades formais:

Más bien, al creer en la "struttura massiccia" de las democracias modernas, con su complicada y compleja organización, hace de la sociedad civil el lugar natural y necesario en donde y por donde conseguir la hegemonía que conlleve a la organización de la lucha revolucionaria. Al extender y 
alargar el ámbito de la hegemonía, al situarla principalmente en el momento del consenso y no sólo en el del dominio (no sólo hegemonía del que ejercita el poder, sino del que quiere conseguirlo), Gramsci hace presente, al mismo tiempo, el momento de la lucha por una reforma moral e intelectual que puede y debe empezar en todos los frentes y no sólo detrás de las barricadas o en los círculos de poder. Lucha por el consenso aún antes de tomar el poder. Es la labor precisa y específica del "dirigente".

Em todo caso, a hegemonia é definida como uma espécie de etapa superior no desenvolvimento de uma força social, na qual se passa a um momento de direção intelectual e moral até o ponto em que a classe passa do particularismo ao universalismo e dirige os outros grupos sociais. À diferença de Lenin, que privilegiava a condução política e militar, Gramsci privilegia a direção cultural e ideológica (Portelli, 1977, p. 78).

Se, por um lado, Gobetti aproxima o liberalismo da via revolucionária violenta, por outro, Gramsci abre a possibilidade, dentro do marxismo, de uma transformação radical que também utilize a estratégia da via democrática para a construção da hegemonia. Estavam colocados os alicerces para o diálogo.

Além desse patrimônio cultural compartilhado, a trágica experiência do fascismo e a luta contra esse regime, sobretudo através da Resistência, incentivaram fortemente as reflexões sobre as liberdades civis e políticas e sobre os procedimentos e instituições jurídico-políticas da democracia liberal, particularmente a defesa da Constituição de 1947. Em um discurso pronunciado em 1954, Lelio Basso confirma que a Constituição, no espírito dos constituintes ${ }^{3}$ - entre os quais se encontrava ele mesmo

\footnotetext{
${ }^{3}$ O resultado da votação de 1946 que elegeu os integrantes da Assembleia Constituinte foi o seguinte: Partido Democrata Cristão 35,2\% (207 cadeiras); Partido Socialista 20,7\% (115 cadeiras); Partido Comunista 18,9\% (104 cadeiras); União Democrática Nacional 6,8\% (41 cadeiras); Partido Republicano 4,4\% (23 cadeiras); Partido da Ação 1,5\% (7 cadeiras); representando a posição contrária àquela do Comité de Liberação Nacional e portanto aos ideais
} 
e Palmiro Togliatti -, tinha traduzido, embora de forma imprecisa e imperfeita, o espírito da Resistência: o respeito pela democracia entendida em um sentido amplo e aberto: não somente a democracia formal das instituições jurídicas, mas uma democracia palpitante de vida, palpitante de participação popular (Basso, 1954).

Consequentemente, não chama a atenção que - tendo em vista a recente experiência do fascismo - o tema-chave em torno do qual se desenrolaram as discussões entre liberais, socialistas e comunistas, a partir do final da Segunda Guerra, tenha sido a democracia liberal em relação ao projeto socialista defendido pelo $\mathrm{PCl}$, surgindo, a partir dele, questões como a relação entre política e cultura, os limites ao poder do Estado, os procedimentos formais da democracia burguesa, as formas de representação política, dentre outros.

O intenso diálogo entre Bobbio e os intelectuais do $\mathrm{PCl}$ começa na década de $1950^{4}$, quando, em 1951, Bobbio publica o artigo: "Convite ao Colóquio", chamando à necessidade de refletir sobre o papel político dos "homens de cultura", sobre os intelectuais e o seu compromisso com a sociedade. Vinte anos mais tarde, Bobbio repete a provocação, desta vez com o artigo: "Existe uma Teoria Marxista do Estado?".

da Resistência estava a formação do Homem Comum (Uomo qualunque), que obteve 5,3\% dos votos e 30 cadeiras. Os demais constituintes $(7,2 \%)$ pertenciam a diferentes agrupações menores, entre elas a dos monarquistas.

${ }^{4}$ Lembremos que o diálogo entre Bobbio e os marxistas se desenvolve ao longo de toda a vida do autor, destacando-se os debates: Política e cultura (1951-1955), Gramsci e a concepção da sociedade civil (1967-1968), O marxismo e o Estado (1975-1977), Qual pluralismo? (1976), A anomalia italiana (1964-1994), Terceira via e terceira força (1978-1979) e Direita e esquerda (1994-1999) (Bobbio, 2012). 
Os textos constitutivos dessa singular polêmica sobre a política, o Estado, a democracia e o socialismo foram publicados entre 1975 e $1976^{5}$. As questões nodais que abriram as discussões foram as afirmações de Bobbio sobre a teoria do Estado e da política no marxismo:

Repito que Marx e Engels, e com maior razão um chefe revolucionário como Lênin, possuíam seus bons motivos históricos para dar mais importância ao problema dos argumentos do que ao das instituições. Mas isto não nos exime de tomar conhecimento de que suas indicações sobre o problema das instituições foram sempre genéricas, sumárias, e o que é mais grave, irreais, e que portanto sua teoria do Estado é incompleta, faltando-lhe justamente aquela parte que induz a muitos reconhecer, com razão, que uma verdadeira e própria teoria socialista do Estado não existe (Bobbio, 1979, p. 29).

Para chegar a essas conclusões, Bobbio parte de uma interpretação ortodoxa (mecanicista, economicista) do marxismo ${ }^{6}$, que pauta a concepção de Estado em Marx pelos seguintes princípios: a.- Marx tem uma concepção negativa do Estado - à diferença do pensamento político que vai de Hobbes até Hegel - que o considera como parte da superestrutura e instrumento de dominação de classe, tendo, portanto, sempre caráter autoritário; b.- a passagem do Estado burguês para o Estado proletário implicaria, além da tomada do poder, a destruição de todas as instituições jurídico-políticas pelo fato de serem liberal-burguesas; c.- a ditadura do proletariado (segundo as indicações de Marx que aparecem nos escritos sobre a Comuna de Paris) corresponderia a um sistema de autogoverno dos trabalhadores, em que se suprimiria a divisão dos poderes do modelo liberal e se instauraria um sistema de representação democrática que incluiria o princípio da revogação

${ }^{5}$ Os artigos foram publicados nas Revistas Mondoperario, Avanti!, Rinascita, La Repubblica, Corriere della Sera, Aut Aut, Nuovo Impegno, Paese Sera-libri, Il Popolo, Aquinas, e Sociologia del Diritto.

${ }^{6}$ Essas ideias se repetem em vários textos de Bobbio, mas estão mais bem explicitadas em: Bobbio et al., 1979 e Bobbio, 2006. 
Sociologias, Porto Alegre, ano 17, o 38, jan/abr 2015, p. 254-279

do mandato; d.- eliminadas as classes, a extinção do Estado se produziria processualmente ao longo do período do Estado de transição.

Em decorrência dessa leitura, Bobbio conclui que o marxismo não possui uma teoria sobre o Estado e sobre as instituições jurídico-políticas capaz de viabilizar a passagem do capitalismo ao socialismo, e isso se deve - segundo o autor - aos seguintes motivos: em primeiro lugar, a preocupação com a conquista do poder (quem governa) é muito maior que a preocupação com o seu exercício (como se governa), negligenciando-se a questão dos procedimentos; em segundo lugar, a possibilidade da extinção do Estado não passa de uma ilusão; e em terceiro lugar, o abuso do princípio de autoridade com respeito a Marx, daí a posição de Bobbio de defender uma "relação laica" com Marx, considerando-o como um pensador clássico e não como uma referência suprema da qual se aguardam todas as respostas, sobretudo, porque uma primeira consequência do abuso do princípio de autoridade é sempre o embotamento do espírito crítico (Bobbio, 1979, p. 19).

Bobbio afirma que as instituições liberais, tais como a divisão de poderes e a democracia representativa, são conquistas civilizatórias que devem conservar-se no Estado de transição ao socialismo, principalmente devido a que são instituições que garantem a liberdade negativa, considerada como pressuposto e complemento da liberdade positiva e da liberdade como autonomia. Isso porque a liberdade negativa leva ao controle do poder e à garantia dos direitos individuais que devem manter-se no socialismo e no processo que a ele leva (período do Estado de transição). Desse modo, embora até aquele momento não tivesse acontecido - e Bobbio é bastante pessimista a respeito - a única via possível ao socialismo é a via democrática:

A relação entre democracia e socialismo é configurada como uma relação entre meio e fim, onde a democracia desempenha a parte do meio e o socialismo a final. [...] A democracia é o único meio possível ou lícito para chegar a uma sociedade socialista. [...] Quando contrapõe-se 
o caminho democrático para o socialismo ao caminho não democrático, o que muda é apenas o conceito do meio ou a visão do fim? (Bobbio, 1979, p. 247-249)

A necessidade de responder às provocações colocou aos marxistas italianos pelo menos três desafios: em primeiro lugar, o de refletir criticamente sobre o conteúdo das afirmações do filósofo turinês; em segundo lugar, o de questionar o "modelo soviético" de transformação social; em terceiro lugar, o de expor os fundamentos da "via italiana ao socialismo", que já vinha sendo desenvolvido desde os anos do pós-guerra.

Os textos nos quais Bobbio expressa suas ideias são os conhecidos ensaios "Existe uma Doutrina Marxista do Estado?" e: "Quais as Alternativas para a Democracia Representativa?", publicados em 1975 na Revista Mondoperaio (Bobbio, 1979, p. 33-54), seguindo-se a polêmica com a publicação das réplicas por parte de intelectuais marxistas e com outros dois textos de Bobbio ${ }^{7}$. Como já assinalamos, o especial valor heurístico

\footnotetext{
${ }^{7}$ Os artigos publicados em ordem cronológica foram: g. d, Il marxismo e lo stato moderno; U. Cerroni, Esiste una scienza politica marxista? Discutendo con Norberto Bobbio; M. Boffa, Le due repliche della storia. Ancora a proposito del saggio di Norberto Bobbio; R. Guiducci, La città dei cittadini e la società dei socialisti; D. Setembrini, Socialismo marxista e socialismo liberale; R. Guastini, Note intorno a un dibattito in corso: dittatura proletaria e democrazia rappresentativa; V. Gerratana, Quando la democrazia è sovversiva. Un intervento nella discussione sul saggio di Norberto Bobbio; A. Occhetto, Sul concetto di 'democrazia mista'. Intervento nel dibattito suscitato dal saggio di Norberto Bobbio. F. Diaz, Teoria dello stato e volontà politica. G. Vacca, Discorrendo di socialismo e di democrazia. L. Cafagna, La fattoria delle "anime morte". G. Vacca, Discorrendo di socialismo e democrazia (II). P. Ingrao, Democrazia borghese o stalinismo? No: democrazia di massa. A proposito del saggio di Norberto Bobbio; N. Bobbio, Perché non possiamo non dirci marxisti, entrevista concedida a F. De Luca; F. Ferrarotti, Marx usato contro Marx; Ulisse, Chi è rivoluzionario; B. Cermignani, Anche Bobbio sbaglia nell'uso di Marx; A. Negri, Esiste una dottrina marxista dello stato?; C. Signorile, La democrazia che trasforma lo stato; A. Macchioro, Socialismo e democrazia garantista; G. Ruffolo, Eguaglianza e democrazia nel progetto socialista; N. Bobbio, Quale socialismo?; O. Pompeo Faracovi, Dunque, quale socialismo; U. Rescigno, Democrazia borghese e democrazia proletaria. A proposito del dibattito fra Bobbio, Cerroni e altri; U. Cerroni, Replica a Bobbio senza diplomazia. La polemica sul marxismo; U. Galeazzi, La mancanza di una teoria marxista dello stato; F. Viola, II socialismo alla prova della democrazia; V. Ferrari, Socialismo e democrazia liberale. A proposito di alcuni recenti scritti di Norberto Bobbio. Todos os textos encontram-se disponíveis em: Bobbio, 2012. A maior parte foi publicada em língua portuguesa em: Bobbio, N. et al., 1979.
} 
desse debate reside em que, nas respostas às afirmações iniciais de Bobbio, os intelectuais que dele participaram expuseram os princípios fundamentais da possibilidade de uma via democrática no sentido não apenas formal das regras do jogo ${ }^{8}$, mas de construção do socialismo na Itália. Tal como afirmava Boffa (1979, p. 91):

O último ensaio de Norberto Bobbio, publicado recentemente no "Mondoperario", não parece estar destinado a passar despercebido. De fato ele repropõe (...) o tema já clássico da relação entre democracia e socialismo. [...] Ele serve de cenário para um intrincado novelo de problemas teóricos que, apesar de ocuparem ha tempos nosso pensamento, está distante (...) de ser desenrolado exauridamente.

$\mathrm{Na}$ análise das divergências e das concordâncias com as afirmações de Bobbio, defrontamo-nos com um complexo esforço de construção perante a necessidade de responder a questões teóricas e políticas urgentes, tais como: o futuro do socialismo e a instância democrática, o aumento dos problemas da organização institucional de sociedades cada vez mais complexas, os "paradoxos da democracia" ${ }^{\text {, }}$ a crítica de esquerda ao Estado

\footnotetext{
${ }^{8}$ Bobbio apresenta algumas "regras" caracterizadoras de um conceito de democracia: 1) todos os cidadãos que tenham alcançado a maioridade, sem distinção de raça, religião, condição econômica, sexo, etc. devem gozar dos direitos políticos, isto é, de expressar através do voto a própria opinião e/ou eleger quem se expresse por ele; 2) o voto de todo os cidadãos deve ser de peso igual; 3) todos os cidadãos que gozam dos direitos políticos devem ser livres para votar, conforme opinião própria formada o mais livremente possível, isto é, numa competição entre grupos políticos organizados que disputam entre si para agregar os anseios e transformá-los em deliberações coletivas; 4) possibilidade de escolha entre alternativas reais, entre soluções diferentes; 5) princípio da maioria numérica, tanto na eleição dos representantes quanto nas deliberações coletivas; 6) nenhuma das decisões tomadas pela maioria, deve limitar os direitos da minoria, em particular o direito de tornar-se maioria em igualdade de condições (Bobbio, 1979, 34).

${ }^{9}$ Bobbio menciona os seguintes paradoxos da democracia moderna: 1) pedimos sempre mais democracia em condições objetivas cada vez mais desfavoráveis; 2) cada aumento das funções do Estado converte-se em um crescimento do aparato burocrático de estrutura hierárquica e não democrática; 3) o desenvolvimento técnico das sociedades industriais leva a que o protagonista da sociedade seja o especialista, e não o cidadão, tornando as decisões cada vez mais técnicas e cada vez menos políticas; 4) o efeito da massificação é o conformismo generalizado e a repressão ou supressão do sentido de responsabilidade individual, base da sociedade democrática (Bobbio, 1979, p. 36-41).
} 
Sociologias, Porto Alegre, ano 17, oo 38, jan/abr 2015, p. 254-279

representativo, os limites das liberdades civis e políticas no capitalismo, as alternativas ao sistema representativo liberal do parlamentarismo clássico.

Mas, sempre no centro das discussões, está a democracia em relação ao socialismo, a possibilidade da conquista do poder através de procedimentos constitucionais, o conceito e a oportunidade histórica da ditadura do proletariado.

Segundo Vacca (1979, p. 177-178):

Parece-nos que o problema da democracia (aquela a ser defendida não menos que aquela nova a ser criada) se entrega inteiramente às maneiras, às formas, à pluralidade dos protagonistas da transformação socialista e da passagem para a nova sociedade. [...] É o caráter do processo ao qual aderimos que coloca à classe operária o problema de religar suas instituições políticas e teóricas a seus valores, às instituições políticas, às tradições culturais, os valores ideais de outros componentes do novo bloco histórico.

Explicitando o nó da questão: o "reajuste", a releitura crítica dos problemas institucionais e processuais da democracia socialista, ainda a crítica ao modelo soviético e o problema colocado à classe operária de "religar" suas instituições políticas e suas teorias a um projeto hegemônico no novo bloco histórico.

IV

Da leitura das posições teóricas e políticas presentes nos artigos que constituem o debate, podemos concluir que o fio condutor se encontra na afirmação da necessidade de socializar o poder político, além de socializar a economia, já no período de transição ao comunismo, e que os procedimentos e instituições vislumbrados como adequados para essa socialização não poderão surgir do simples desprezo pelas instituições 
jurídico-políticas da democracia burguesa, antes bem da reavaliação e reapropriação crítica das mesmas.

Em outras palavras:

Énecessário que a democracia se desenvolva com coerência no plano econômico e político. E é aqui que surge o verdadeiro problema (...): não só não pode existir uma doutrina marxista que omita o nexo entre economia e política, como também é impossível um discurso sobre as instituições que não se posicione como centro do mecanismo de produção (Occhetto, 1979, p. 111-112).

A partir desse pressuposto, foram desenvolvidos pelos autores temas fundamentais os quais, para efeito dos objetivos deste trabalho, organizamos em: a ciência política, o Estado, as consequências do fascismo, a concepção de ser humano. Tomamos para as nossas análises as reflexões daqueles intelectuais marxistas que apresentam abordagens abertas ao diálogo com posições teóricas democrático-liberais. No debate, várias posições refletiram as diferentes tendências no interior do $\mathrm{PCl}$, desde aquelas que negaram por completo as afirmações de Bobbio, até as que aceitaram boa parte dos argumentos apresentados.

Na ciência política marxista, faltou um interesse específico pela teoria política e pela teoria do direito. Essa afirmação de Bobbio é compartilhada por Cerroni (1979), para quem as causas dessa ausência devem ser buscadas no achatamento economicista sofrido, em um primeiro momento, e na redução político-pragmática, em um segundo momento, atendendo-se preferencialmente aos assuntos da organização do partido em vez de ocupar-se do Estado:

O reducionismo economicista do marxismo tem uma longa história que, para efeitos da teoria política, sempre resumi nestes termos: a justa crítica trazida no marxismo às liberdades formais ou políticas foi sempre compreendida como proposta de substituí-las com a liberdade real ou social. De 
tal modo, a democracia socialista foi pura e simplesmente contraposta por substituição à democracia política, se bem que esta última tenha sido em larga medida não somente uma solicitação, mas também uma conquista do movimento operário socialista (Cerroni, 1979, p. 56-57).

No mesmo sentido, Guiducci (1979) chamava a atenção para o fato de ter-se identificado poder coercitivo com exploração da sociedade privada e, como corolário, ter-se concluído que, com a eliminação da propriedade privada, eliminar-se-iam as classes, e que, finalmente sem classes, o Estado desapareceria. Occhetto (1979, p. 113) - concordando com Cerroni - manifestava a urgência de colocar-se na direção da superação de uma visão que reduz o Estado a simples organização da violência e na consecução de uma concepção que nos remete ao terreno gramsciano da hegemonia.

O ocorrido na União Soviética foi - ao contrário da socialização do poder - a privatização do poder, encarnada no Estado soviético: A propriedade priva os outros homens dos objetos, do dinheiro, das faculdades, etc.; o poder priva os outros homens das escolhas, das determinações, da possibilidade de explicação da personalidade (Guiducci, 1979, p. 70). Essa privatização do poder foi a mais dura "réplica da história" que o $\mathrm{PCl}$ precisou enfrentar, e o fez elaborando uma teoria política socialista original (Boffa, 1979, p. 92) a qual, renunciando ao abuso do princípio de autoridade das teses de Marx - condutor do dogmatismo duramente criticado por Bobbio (1979, p. 17-19) -, permitiu escolhas políticas que modificaram o próprio horizonte teórico:

A "política" cumpriu escolhas que modificaram implicitamente o horizonte teórico, no qual se posiciona a reflexão sobre o socialismo, indicando novos caminhos ainda inexplorados a serem percorridos, elaborando uma concepção inédita em muitos ângulos da conquista do socialismo que não tem precedentes na história do movimento operário (Boffa, 1979, p. 92-93). 
Tratava-se, todavia, de um processo inacabado diante dessa elaboração que: Embora tenha chegado a enfatizar o caráter inseparável do binômio democracia-socialismo, não pôde, contudo, evidenciar de forma adequada a natureza paradoxal de muitos lados deste binômio (Boffa, 1979, p.93).

No que tange ao tema do Estado, segundo Cerroni (1979), houve uma subestimação, por parte dos marxistas, dos problemas específicos sobre os quais a cultura burguesa refletiu e elaborou as suas teorias, afirmando-se que careciam de uma relação objetiva com a realidade e que, portanto, eram apenas simples invenções para enganar aos proletários. Consequentemente, se interpretou o Estado como mera máquina criada para a repressão violenta, e o sufrágio universal como um complemento do formalismo burguês. Mas essa perspectiva muda com Gramsci:

\begin{abstract}
Não encontro entre os marxistas ocidentais nenhum que tenha entendido a profundidade deste problema tanto quanto Gramsci. Ele é o primeiro a não se deixar ofuscar, no problema do Estado, pelo forte elemento da violência, e compreende que, na realidade, em um Estado fundado sobre democracia política, o mesmo exercício da violência por parte do Estado é condicionado à capacidade de capturar e manter um consenso (Cerroni, 1979, p. 58-59).
\end{abstract}

O problema do Estado se redimensiona, Gramsci

[...] Coloca às claras que o Estado não é um genérico aparelho de violência, [...] mas um específico aparato onde o próprio mecanismo varia em razão da organização social da produção até se tornar estado representativo constitucional, baseado sobre a formal igualdade de todos, também dos proletários, na determinação da elite política que exerce o poder (Cerroni, 1979, p. 59).

Assim, a questão política se entende como a questão da capacidade hegemônica da classe dirigente para transformar a sociedade, inserida em um processo histórico - não genérico -, abrindo-se a possibilidade de que as garantias formais individuais da democracia política não sejam necessa- 
riamente eliminadas, mas incorporadas e redefinidas hegemonicamente nesse processo: O problema não é somente teórico: concerne à capacidade hegemônica da nova classe dirigente e também à possibilidade de que a transformação da sociedade aconteça sem eliminar as garantias formais do indivíduo, que são relativas à democracia política (Cerroni, 1979, p. 59).

A experiência fascista (1919-1945) exigiu dos marxistas italianos uma profunda reflexão sobre a democracia e sobre as várias formas de expressão do domínio da classe dominante, levando à conclusão de que reduzir a democracia a mero formalismo jurídico e burguês termina por falsear a relação entre democracia e socialismo, reduzindo a democracia a um simples instrumento, sem nela reconhecer os valores permanentes e o próprio caráter de conquista e alvo do movimento operário (Occhetto, 1979, p. 109-110). Na Itália a democracia política de pós-guerra se expande graças ao movimento socialista que foi necessariamente antifascista:

O movimento socialista, na sua batalha anticapitalista, deve necessariamente desenvolver uma batalha antifascista e de promoção da democracia política. Mas isto significa também que se traça a necessidade de substituir o capitalismo se se quiser fazer progredir a democracia e a possibilidade de fazer avançar o socialismo com a democracia. (...) A democracia política empurra para o socialismo e o socialismo empurra para a democracia política (Cerroni, 1979, p. 64-65).

Em tom de autocrítica, Cerroni (1979, p. 66) levanta a hipótese de ter sido o desinteresse pela democracia política que permitiu a vitória do fascismo e a derrota do socialismo na Itália. Mais ainda, a expansão da democracia política é um aspecto específico da luta contra o capitalismo e pela construção das formas políticas de um socialismo evoluído.

Occhetto (1979, p. 110) - referindo-se à adoção da "via italiana ao socialismo" -, salienta o valor das mudanças introduzidas por Togliatti, considerando a conquista e a abertura democrática como objetivo consciente e produto direto da ação proletária, vivida historicamente como 
democracia progressiva e como uma possibilidade que interessa apenas ao proletariado. Para esses marxistas a transição para o socialismo segue uma estratégia de transformação revolucionária gradativa (...) colocando bem antes da tomada de poder a possibilidade de reformas estruturais, ou como foi dito recentemente por Berlinguer, a introdução de 'elementos do socialismo' (Occhetto, 1979, 111).

Outro tema fundamental que aparece no bojo da proposta italiana ao socialismo e que não podemos deixar de mencionar é a necessidade de enfrentar o problema da transformação do ser humano através de uma antropologia marxista. Setembrini assinala a diferente forma em que o socialismo liberal e o socialismo revolucionário se colocam perante este assunto. Para ambas as posições, é possível a transformação do ser humano, mas enquanto para a primeira é necessário que exista o consentimento dos interessados, para a segunda - que parte da hipótese da corrupção da natureza humana - a mudança deverá acontecer com ou sem consentimento dos interessados, já que a finalidade é mudar a natureza humana. Então, se pergunta o autor: Mas, se a maioria, proletária ou não, não quiser saber do socialismo? (Setembrini, 1979, p. 88).

A questão não é menor, assumindo que o socialismo não é apenas a efetivação da justiça social, trata-se também de uma particular relação entre indivíduo e comunidade:

É uma nova disciplina das forças produtivas, o controle e o domínio dos processos espontâneos e, por definição, refratário a toda interpretação exasperadamente libertária da relação entre indivíduo e comunidade. Tende a criar uma nova hierarquia de valores, a atribuir um papel inédito ao indivíduo e à comunidade da qual faz parte (Boffa, 1979, p. 95).

O marxismo italiano desse período não avançou muito mais nessa questão, mas o rumo das discussões que enfrentou permitiu ao menos reconhecer a importância fundamental de refletir sobre a concepção de 
"natureza humana", se inicialmente boa e corrompida ou se historicamente construída.

O contexto histórico da Itália - a experiência fascista, a guerra, a crise do bem estar social - e a crise do modelo soviético, junto com a tradição teórica do marxismo de Gramsci, levaram a que o $\mathrm{PCl}$, além de produzir reflexões teóricas singulares, conseguisse implementar uma política inovadora coerente com essas teorizações. Essa particular relação entre a política e a teoria é uma das principais contribuições do marxismo italiano desse período.

A presença de Gramsci é fortíssima, às referencias expressas ou implícitas aos Cadernos do Cárcere se repetem em cada texto, especialmente aquela pergunta que indica o verdadeiro problema da democracia:

\footnotetext{
Deseja-se que se tenham sempre governados e governantes, ou então quer-se criar as condições nas quais a necessidade da existência desta divisão desapareça? Isto é, parte-se da premissa da perpétua divisão da espécie humana ou acredita-se que esta seja somente um fato histórico, que responde a certas condições? (Cerroni, 1979, p. 67; Guiducci, 1979, p. 78).
}

Passados quase quarenta anos dessas polêmicas em torno ao Estado, à democracia e ao socialismo, continua vigente o interesse pelas questões levantadas. Continuamos a perguntar-nos pelas formas institucionais necessárias a um Estado socialista radicalmente democrático. Continuamos a digladiar-nos perante as impossibilidades de conciliar igualdade e liberdade, democracia e socialismo, ao ponto de retomar permanentemente as perguntas: Qual democracia? Qual socialismo?

Provavelmente o problema continue o mesmo: 
Sociologias, Porto Alegre, ano 17, o 38, jan/abr 2015, p. 254-279

[...] Aquele de construir nos países evoluídos um modelo de Estado no qual a passagem para o autogoverno integral dos trabalhadores se baseie na expansão da democracia política, isto é, na progressiva combinação da democracia representativa com a democracia direta, de modo a desenvolver cada liberdade (salvo a de apropriação privada do produto social) e cada forma de participação. Naturalmente, esta ação de socialização do poder deverá acompanhar-se de uma ação progressiva de socialização dos meios de produção. Os tempos e as formas desta ação combinada serão marcadas pelo critério essencial da conquista do consenso, no pressuposto, aqui de todo subentendido, de que o socialismo contemporâneo não é tanto um programa doutrinário a ser "aplicado" (...) quanto, de preferência, uma crítica histórica a ser conduzida pela sociedade capitalista com base nas contradições que ela exprime e também da necessidade que levanta e das instâncias que faz emergir (Cerroni, 1979, p. 62).

Fica o desafio de revisitar o marxismo italiano, de Gramsci a Berlinguer, na certeza da necessidade de - parafraseando Vacca - "religar" os discursos sobre as instituições e procedimentos democráticos aos processos históricos concretos de transformação das sociedades capitalistas em sociedades socialistas.

María del Carmen Cortizo - Pós-doutora pela Università degli Studi di Torino PRINCIPALE(2013). Professora do Programa de Pós Graduação em Serviço Social da UFSC. $>$ maria.ufsc@gmail.com

\section{Referências}

1. BASSO, L. La democrazia non si difende ponendosi contro la Costituzione, «La Squilla», 23 dic. 1954, n. 49, p. 1-2. Disponível em: < http://www.leliobasso. it/testi.aspx>. Acesso em 10/04/2014.

2. BERLINGUER, E. A democracia como valor universal. Setembro, 2006. Disponível em <http://www.acessa.com/gramsci/?id=572\&page=visualizar $>$. Acesso em 26/06/2013. 
Sociologias, Porto Alegre, ano 17, oo 38, jan/abr 2015, p. 254-279

3. BOBBIO, N. Existe uma teoria marxista do Estado? In: BOBBIO, N. et al. O marxismo e o Estado. Rio de Janeiro: Graal, 1979, p. 13- 31.

4. BOBBIO, N. Nem com Marx, nem contra Marx. São Paulo: UNESP, 2006.

5. BOBBIO, N. Quais as alternativas para a democracia representativa. In: BOBBIO, N. et al. O marxismo e o Estado. Rio de Janeiro: Graal, 1979, p. 33-54.

6. BOBBIO, N. Qual socialismo? In: BOBBIO, N. et al. O marxismo e o Estado. Rio de Janeiro: Graal, 1979, p. 233-251.

7. BOBBIO, N. Ritratto di Piero Gobetti (1901-1926). In: MORRA DI LAVRIANO,

U. Vita di Piero Gobetti. Turim: UTET, 1984, p. 7-26.

8. BOBBIO, N. et al. O marxismo e o Estado. Rio de Janeiro: Graal, 1979.

9. BOFFA, M. As duras réplicas da história. In: BOBBIO, N. et al. O marxismo e o Estado. Rio de Janeiro: Graal, 1979, p. 91-98.

10. CERRONI, U. Existe uma ciência política marxista? In: BOBBIO, N. O marxismo e o Estado. Rio de Janeiro: Graal, 1979, p. 55-68.

11. CERRONI, U. Pequeño diccionario gramsciano. Buenos Aires: Altamira, 2008.

12. COUTINHO, C. N. A democracia como valor universal e outros ensaios. Rio de Janeiro: Salamandra, 1984.

13. GUIDUCCI, R. A cidade dos cidadãos e a cidade dos socialistas. In: BOBBIO, N. et al. O marxismo e o Estado. Rio de Janeiro: Graal, 1979. p. 69-78.

14. MONDAINI, M. Do stalinismo à democracia: Palmiro Togliatti e a construção da via italiana ao socialismo. Brasília: Fundação Astrojildo Pereira - Rio de Janeiro: Contraponto, 2011.

15. NOGUEIRA, M. A. Prefácio. In: RÊGO, W. G. D. L. Em busca do socialismo democrático: o liberal-socialismo italiano: o debate dos anos 20 e 30. Campinas: UNICAMP, 2001. p. 19-20.

16. OCCHETTO, A. Sobre o conceito de "democracia mista". In: BOBBIO, N. et al. O marxismo e o Estado. Rio de Janeiro: Graal, 1979, p. 109-117.

17. PIÑON, F. Gramsci: Prolegómenos, filosofia y política. México: Plaza y Valdés, 1989.

18. PORTELLI, H. Gramsci e o bloco histórico. Rio de Janeiro: Paz e Terra, 1977.

19. REICHLIN, A. Apresentação. In: VACCA, G. Por um novo reformismo. Brasília: Fundação Astrojildo Pereira - Rio de Janeiro: Contraponto, 2009, p. 9-30. 
Sociologias, Porto Alegre, ano 17, o 38, jan/abr 2015, p. 254-279

20. REVELLI, M. Gobetti "liberal-comunista"? In: BOVERO, M. et al. (org.). I dilemi del liberalsocialismo. Roma: La Nuova Italia Scientifica, 1994, p. 63-84.

21. SÁNCHEZ VÁZQUEZ, A. Entre a realidade e a utopia: ensaios sobre política, moral e socialismo. Rio de Janeiro: Civilização Brasileira, 2001.

22. SETEMBRINI, D. Socialismo marxista e socialismo liberal. In: BOBBIO, N. et al. O marxismo e o Estado. Rio de Janeiro: Graal, 1979, p. 79-90.

23. TOGLIATTI, P. Socialismo e democracia: escritos escolhidos do período 1944/1964, Rio de Janeiro: Ilha, 1980.

24. VACCA, G. Discorrendo sobre socialismo e democracia. In: BOBBIO, N. et al. O marxismo e o Estado. Rio de Janeiro: Graal, 1979, p. 139-179.

Recebido em: 08/08/2014

Aceite Final: 26/11/2014 